\title{
REVIEW PAPER ON 3D PRINTING CONCRETE TECHNOLOGY AND MECHANICS FROM INDUSTRIAL ASPECT
}

\author{
Adan Bishar Hussein, \\ Master student Department of Civil Engineering, \\ Cyprus International University, Nicosia, Northern Cyprus
}

\begin{abstract}
There were a number of recent construction methods and materials introduced in the 21st century however, because of lack of data, the implementation of a new construction techniques or a replacement material, the limits of architecture and design have not changed considerably, as will the construction methods. Like the building project. In a broad spectrum of fields, the world of foodstuffs, and user management components, technology also showed promises. Similar with any or all sectors, the building industry continues to support the production of 3D printers. 3D printing should not be underestimated because it reduces the scope of key factors such as growth, the cost of the product and the duration of the entire undertaking. The discovery of new printable, refining shapes, and the regular properties of 3D written concrete will realize this inspiring technique in observation.
\end{abstract}

Keywords: 3D concrete printing technology, Contour Crafting, Concrete printing, Additive manufacturing, Environmental effects, Construction cost, Computer Aided Design (CAD)

\section{INTRODUCTION}

Concrete is the most commonly used material for construction on this planet. There are many challenges facing the global concrete construction industry. The high cost is one of these. Recent research by the Boral Innovation Factory [1] has shown that shaping accounts for around $75 \%$ of the total construction costs in Sydney,). This can be a characteristic of worldwide concrete building. Another problem is the considerable measure of waste produced in the construction. Shaped form is an eloquent waste source because sooner or later, all of which are discarded, resulting in an increase in waste in the building industry.

In many fields, 3D printer technology is today used in different areas of application every day: industrial production, medicine and safety, aviation, building and architecture, military applications, fabrics, nutrition and training. The construction sector is still developing 3D printing by comparing all these areas. No one should underestimate the positive effects of the $3 \mathrm{D}$ printing on the construction industry as the various factors in the entire project are reduced, such as design, materials, costs and time. For the first time in 1984, Charles (Chuck) Hull produced a 3-dimensional object using numerical information was realized [Nadarajah 2018]. The virtual 3D template is converted to STL (Stereolithography) format and sent to the 3D printer [2].

$3 \mathrm{D}$ printing creates a concrete object by constructing it layer by layer. It was previously known as Rapid Prototyping. The 3-D printing technology uses a small amount of material and therefore introduces lightness into the products and enables the design of a multi-functional component Astonishing information performed in Llatas [2] indicates that construction is taking charge of for generating about 80th of the world's total waste. However, the traditional method of casting concrete into formwork restricts architects ' structural freedom of design in various geometries, unless the price of customized formwork is very high. Rectilinear forms not only hinder architectural innovation, but due to stress intensity, they are also structurally weaker than curvilinear shapes. The slow rate of construction (i.e. long and difficult to manage lead time) is another obstacle. Concrete construction also requires several phases, including the processing of materials, transport and on-site f production.

According to the Safe Work Australia survey in Australia, an average of 35 building workers were seriously injured every day [3]. In fact, height falls cause over one-quarter of building deaths [3]. In view of Australia's safety requirements at building sites are one of the lowest in the world. Last but not least, there are significant sustainability problems with the current construction sector. Generally speaking, current construction practices and materials are not respectful of the climate. There is immense carbon pollution in the whole of construction, including on-site manufacturing, material transport, installation and assembly and building and high consumption of energy [4]. Therefore, standard Portland cement (OPC) conventional concrete is not sustainable. Highly energy-intensive and carbonintensive production of OPC [5].

Using concrete construction 3D printing techniques maybe help to solve the same challenges. Recently, one by one 3D printing technology is gaining 


\section{International Journal of Engineering Applied Sciences and Technology, 2021 \\ Vol. 5, Issue 12, ISSN No. 2455-2143, Pages 39-48 \\ Published Online April 2021 in IJEAST (http://www.ijeast.com)}

more popularity in the construction industry. Several techniques for $3 \mathrm{D}$ concrete printing (3DCP) have been studied in previous years. This paper discusses 3DCP technology's current progress.

\section{BACKGROUND}

3D printing is a collection of methods designed to build 3D structures from a digital sample in consecutive layers with low wastes directly. This technique is also called Additive Manufacturing (AM). AM was defined as "the process of joining materials to build $3 \mathrm{D}$ model information structures usually layer-by-layer" by the American Society for Testing and Materiel (ASTM) International Committee on Model Technologies [6]. AM technologies were developed in the early 1980s. AM technologies are now a part of new product expansion and are successfully applied to a vast amplitude of industries, including aerospace and automotive industries, consumers, food and biomedicine; [7]

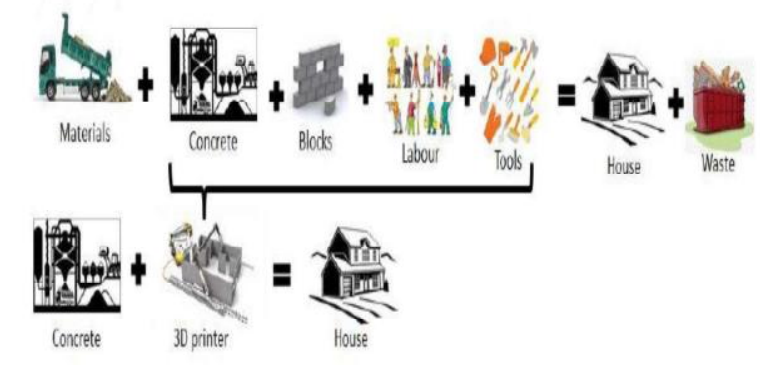

Fig -1: Rapprochement of traditional construction and 3D printing construction process (Nadarajah 2018)

\subsection{ADDITIVE MANUFACTURING}

Additive production, as opposed to the ASTM subtractive design methodologies, is defined as a mechanism by which the artifacts of 3D models are transformed into a material component, typically layer by layer. Synonymous uses include processing of additives, methods of additives, additive technologies, additive sheet manufacturing, surface processing, and freeform manufacturing (ASTM F2792-10). Typically AM innovations consist of device use, 3D modelling technology (Computer-Aided Design (CAD)), desktop devices, and layering materials, all of which are jointly presented in Figure 2. The file will be transferred to the AM tools after a CAD draft is created and the laptop will read the information from the $\mathrm{CAD}$ folder. After that, the object is created in its 3-dimensional structure by placing the material on top of each other in layers. Unique materials such as powder, liquid and steel plates (Chang 2016) can be used to create the object.

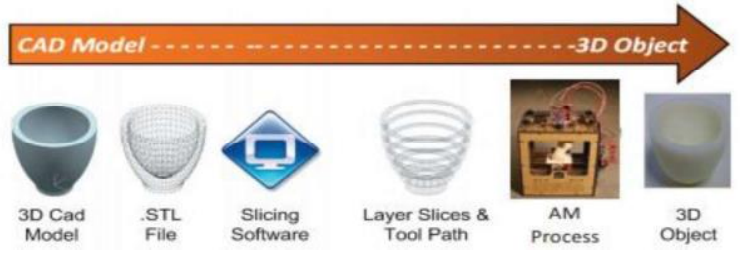

Fig- 2. Generalized Additive Manufacturing Process (Campbell et al. 2011).

since the mid-1960s, the layered production process has been used and there are several advances in the use of materials. This process has been used in concrete production meanwhile the mid-1990s (Bos et al. 2016). The word layered manufacturing this includes a range of techniques that can quickly generate similar objects, such as RP, Layered Manufacturing (LM) and 3D printing. Layer production, now known as 3D printing manufacturing was very effective in reducing the expense of the length of the production process (Nadarajah 2018). In the construction sector, AM has significant advantages.

For example, AM offers up to 30 percent reduction in waste materials and energy consumption, in-situ output, reduction in the use of raw materials and $\mathrm{CO} 2$ emissions, and even more architectural / design advantages compared to general techniques (Gebler et al. 2014; Bos et al. 2016). However, AM processes often involve disadvantages to conventional methods of construction and production, such as slow printing speed, high precision, surface quality, the need for careful selection of materials and low mechanical properties (Hopkinson et al. 2006).). In the aerospace and automotive industries, $\mathrm{AM}$ processes are used in software manufacturing, the production of small parts is used in medical applications and architectural modeling. Research on free-form structures began in 1997.

Pegna (1997) has shown that the complexity of the construction method could be compact by reconstruction with a number of basic operations and that the threedimensional shape could be achieved by layered development by placing a layer of reactive material (Portland cement) on a surface. Large-scale construction sector began adopting AM techniques after this initiative. The use of AM may be modified in accordance with the designer's working method and design processes. In this regard, there are currently three main AM processes worldwide: I Crafting (America), ii-Dshape (Italy) and iii-Concrete Printing (UK).

These three approaches have shown that large-scale components can be efficiently manufactured and are ideal for building and/or design applications and have started to replace traditional construction processes. 


\section{International Journal of Engineering Applied Sciences and Technology, 2021 \\ Vol. 5, Issue 12, ISSN No. 2455-2143, Pages 39-48 \\ Published Online April 2021 in IJEAST (http://www.ijeast.com)}

\subsubsection{Contour crafting $(\mathrm{CC})$}

Contour Crafting (Lim et al. 2012), a layered manufacturing system with robotic arms and extrusion nozzles, is one of the major developments in AM technologies in the construction industry. Khoshnevis \& Bekey (1998) (University of Southern California) first used the Contour Crafting (CC) technique, which is one of the origins of $3 \mathrm{D}$ concrete printing and is still used. From then until now the development of this technique was critical.. In the layered production method used to create large-scale objects with a smooth finished surface, polymer, ceramic paste, cement, and various other materials and mixtures were used (Wolfs 2015). The CC process is a process that simulates, but is performed with some automation, the traditional construction process. The CC process is an interesting design, the mould is not removed and becomes a part of the wall, needs three different steps as a moulding, strengthening and placement. Different materials can also be used with the CC process, such as ground aggregates, strengthening fibres and additives, and the nozzle may also be deflected to form non-orthogonal surfaces like domes and vaults. NASA was also interested in the management of space research with Contour Crafting. It has been observed from the experiments on the $\mathrm{CC}$ that the method is also promising in possible moon buildings (Khoshnevis and Zhang et al. 2018).

\subsubsection{D-shape}

Italian civil engineer Enrico Dini invented a Dshaped three-dimensional printer. It was founded in 2004 and claimed the world's first 3D printing technology to consolidate crushed calcareous dolomite into a material of solid stone. The goal of Enrico was to create 3D printed structures with local materials. It was a natural tester with a wide array of crushed rock aggregates, like volcanic rock and marble, successfully tested (Nadarajah 2018; Anonymous 2019(a)). The D-fit process is based on the injection of the binder into the material's surface. This is intended to print works using an inorganic sand binder in 5-10 mm layers. It uses an advancement process same to the powder-jet printing process in the binder so that the desired layers of the material are formed (Cesaretti et al. 2014). The process is based on a powder deposition process. The downside of those processes is that the final structure must be cleaner from the residual dust into the after-treatment form and that more care, cleaning and control is needed. The extraction of the unused product dust and the grinding and polishing of the ground form part of the post-processing cycle (Lim et al. 2009). The D-Shape is a big, numerically crafted $3 \mathrm{D}$ printing system from the underpass to the roof with foundations and partitions ceilings, staircases, gaps.

\subsubsection{Concrete printing $(\mathrm{CP})$}

Another large-scale 3D concrete printing is the building process. As the print head used for cement mortar extrusion is also placed on top of the crane, it is same like Contour Crafting for concrete printing. The printing nozzle is traveling along a preprogrammed course and the concrete materials are constantly extruded. The 3D CP process has less deposition resolution compared to Contour carving, which allows better control of complex geometries. CP is capable of producing highly customized building components (Ma et al. 2018). CP uses a single nozzle, unlike D-Shape, which ensures that the structure has only the requisite material volume; however, an approach with one nozzle ultimately restricts the deposition speed, as the nozzle has to circulate throughout the structure (Lim et al. 2012). As with most AM processes, extrusion is based on a cement-based mortar which provides data preparation, the preparation of materials, mechanical and other features (Lim et al. 2011). At the Department of Civil and Structural Engineering at Loughborough University, the concrete printing (CP) technique was developed to be used in extrusion-based construction processes in a manner similar to CC. In addition to achieving $100 \mathrm{MPa}$ compressive strength and $10 \mathrm{MPa}$ bending strength in 28 days, a high-performance printing concrete was developed based on the criteria of workability, extrudability and buildability (Le et al. 2012 (b); Le et al. 2012 (a);). Table 3, Figure 3. Displays the elements generated by CC, D-shape and CP methods.

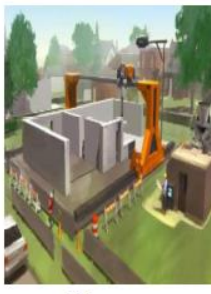

$\mathrm{CC}$

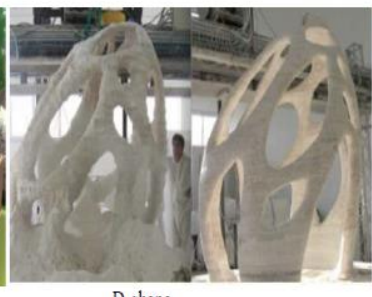

D-shape

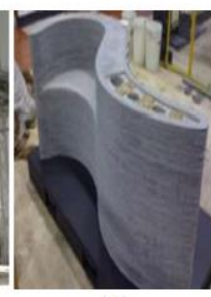

$\mathrm{CP}$
Fig -3: shows the elements in which CC, D-shape and CP methods are produced.

\section{METHOD AND APPROACH}

This paper offers a formal overview of it and addresses the technical issues and solutions related to 3D Concrete Printing:

- Requirements of concrete for 3D printing

- Mechanical properties of 3D printing concrete

A comprehensive literature review in the 3DCP region led to 50 to 60 topical papers filtered with the exclusion of review papers and research not focusing on motoric extrusion-based 3DCP. The remaining papers were checked to see whether they presented scientific evidence or analysis. Observations were focused either on formal analysis or experience and were both included in a basis of evidence of approximately eight papers.

The purpose of the study is to provide a state-of-theart analysis, which can be easily illustrated and linked to key fields of materials research, to mark the recent papers on this topic. This describes the interdependent factors that affect the design and dynamics of the system and control the process at the same time. Then these 


\section{International Journal of Engineering Applied Sciences and Technology, 2021 \\ Vol. 5, Issue 12, ISSN No. 2455-2143, Pages 39-48 \\ Published Online April 2021 in IJEAST (http://www.ijeast.com)}

arguments and their interrelationships are compared to create a matrix of research and development problems that impact on the application of manufacturing. This matrix is provided to provide perspective and framework to help frame and guide future research and the growth of the technology exposition. The paper ends with a statement of vision outlining the exacted functionality and design capabilities by manufacturing using 3DCP processes to revitalize creative thinking about the research issues.

\subsection{MeChaniCAL PROPERTIES}

The mix ratio of 3D printing concrete has been optimized after some tests and is shown in Table 1. like the concrete, PO 42.5 cement was used. The fine aggregate used was sand with a modulus of 2.8 in fineness, the coarse aggregate was $5-15 \mathrm{~mm}$ in particle size, and the admixture used as fly ash. The complete amount of cement in the concrete was about 3-5 per cent of the compressor. The printed concrete was originally set at 5 10.

Table 1. 3Dprinted ready mixed concrete mix ratio

\begin{tabular}{|c|c|c|c|c|c|}
\hline Design Strength & Cement & Sand & Aggregate & Water & Admixture \\
\hline C20 & 1 & 3.20 & 3.62 & 0.66 & 0.024 \\
\hline C25 & 1 & 2.98 & 3.40 & 0.60 & 0.032 \\
\hline
\end{tabular}

Concrete was poured into a cube test mold based on the above mixing ratio for print concrete. To evaluate the compressive strength of the material, a Hydraulic Compression Testing Machine (Jinan Chuanbai Equipment, Jinan, Shandong, China) [8] was selected as a norm in China for testing mechanical sections on ordinary concrete. Table 2 shows the results achieved after 28 days for the print concrete and the standard ready-mixed concrete tests.

The strength of the printed concrete can be witnessed as the conventional ready-mixed concrete is reduced by 2 $4 \mathrm{MPa}$. It is asserted that combining an accelerator as the admixture could diminish the print concrete's mechanical strength. The accelerator speeds up the hydration Materials 2019, 12, 15408 of 14 of the C3S, C2S and $\mathrm{C} 4 \mathrm{AF}$ silicate minerals and also creates cracks and voids in the concrete, resulting in a decline of strength for the concrete.
Table 2. Comparison of concrete compressive strength tests.

\begin{tabular}{|c|c|c|c|c|}
\hline Specimen & $\begin{array}{c}\text { Concrete Design } \\
\text { Strength (MPa) }\end{array}$ & Dimension (mm) & $\begin{array}{c}\text { Compressive } \\
\text { Strength (MPa) }\end{array}$ & $\begin{array}{c}\text { Standard } \\
\text { Deviations (MPa) }\end{array}$ \\
\hline Printed & $20 \mathrm{MPa}$ & $150 \times 150 \times 1.0$ & 19.1 & 0.25 \\
\hline Normal & $20 \mathrm{MPa}$ & $150 \times 150 \times 150$ & 23.8 & 0.16 \\
\hline Printed & $25 \mathrm{MPa}$ & $150 \times 150 \times 150$ & 24.1 & 0.30 \\
\hline Normal & $25 \mathrm{MPa}$ & $150 \times 150 \times 150$ & 28.8 & 0.17 \\
\hline
\end{tabular}

\section{DEVELOPMENTS AND REQUIREMENTS}

\subsection{Developments in the 3D concrete printing} technology

In recent years, 3D concrete printing has been developed around the world. The use of cement and concrete materials in conjunction with $3 \mathrm{D}$ printing continues to expand over time. With the support of large first which have embraced and created the 3D Printing Method, the process started with small non-structural applications and started creating large-scale structures. Below is a list of examples from around the world on 3D concrete printing productions.

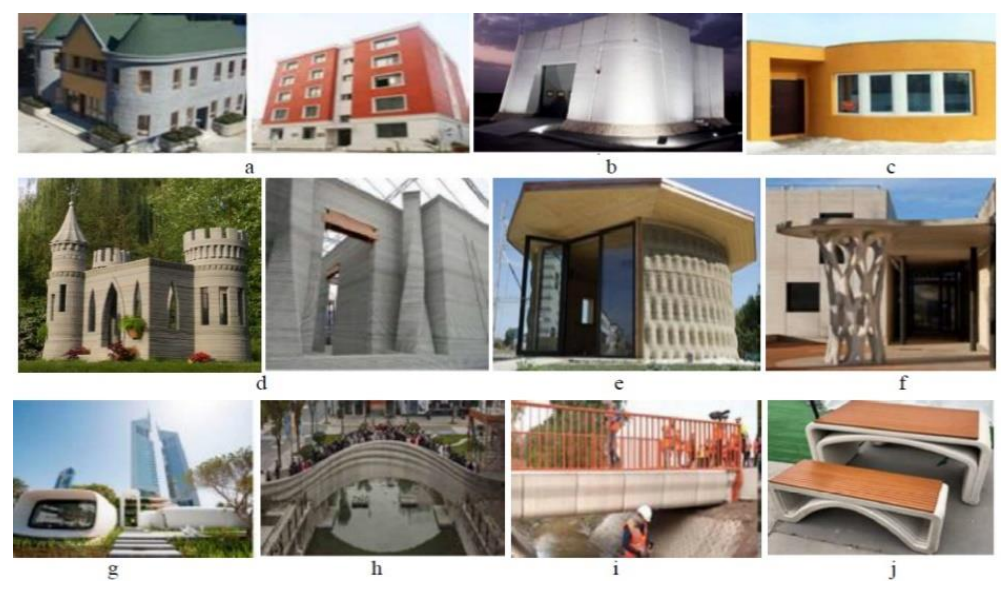

Fig -4: some of the worldwide examples on 3D concrete printing productions.

\subsection{Requirements of concrete for 3D printing}

3D concrete printing technology was developed worldwide in recent years. With the passing of time, the use of concrete and construction materials together with 3D printing continues to increase. The method, which has started with small, non-structural uses, has begun in this context with the growth of large enterprises large structures adopting and developing the $3 \mathrm{D}$ printing method. Below is a list of some of the world's 3D concrete printing productions examples. To excel in 3D 


\section{International Journal of Engineering Applied Sciences and Technology, 2021 \\ Vol. 5, Issue 12, ISSN No. 2455-2143, Pages 39-48 \\ Published Online April 2021 in IJEAST (http://www.ijeast.com)}

printing concrete structures, the following key properties of concrete require improvement:

- Extrudability: Extrusion mechanism is the ability of a concrete pump, transmission tube and spray nozzle to move through without any alteration in its physical properties. The coapplication of self-compacting concrete and shotcrete concepts for the mixture model achieves strong extrudability (Le et al. 2012 (a)). The concrete must have a fluid rate so that the printer can be fed into layers. If there are many architectural specifics in the design, the pressure level must therefore be adjusted so that the tool does not waste the extrusion material. Excessive concrete construction leads to poor coating surface area during printing resulting from incorrect control of the system(Nadarajah2018).

Many studies mention the construction of conc rete layers with extrusion and the fresh concret e properties of 3D concrete, but a suitable test method for evaluating this concrete property $h$ as not been defined.

- Buildability: Constructiveness can be described as the capacity of the concrete layer underneath to hardness and hold other layers before putting the next concrete layer on the printed surface. In this way, an adequate base for building the concrete on each floor is given. The most important elements of $3 \mathrm{D}$ concrete is extrudable and capable of construction both these criteria contribute to the concrete workability (Le et al. (2012) (a)). Bos et al. (2016) found that the sublayers should not be deformed by the weight of the top layer in the 3D production method, but that the interlayers should also bind and be well attached to the top layers to be able to shape. Chemical admixtures, temperature and use of less gypsum cement are factors that affect buildability.

- Workability: The quality of the finished printed design is greatly affected by the fresh concrete quality once the concrete is poured, stays intact and has enough working capacity (can be extruded). The downturn, compression factor and flow steps required for different national standards are traditional methods for assessing operability. Small changes in environmental conditions (temperature, humidity, raw material moisture, etc.) influence the workability of 3D printing concrete (Papachristoforou et al. 2018). To order to increase the workability of the modifying agent of the 3D concrete mixture viscosity, the mixture must have a small particle size to match the diameter of the nozzle. The modification of the pumpability and extrudability workability of $3 \mathrm{D}$ concrete is close to the Shotcrete Concrete wet system development (Lim et al. 2011). The use of viscosity-modifying agents in $3 \mathrm{D}$ concrete printing is important Because the rheology is modified by applying thixotropic properties to the concrete. Thus, the viscosity of the concrete decreases when the strength is applied and when power is stopped, it increases the viscosity so that the concrete is given a good speed resistance (Ozalp et al. 2018) It decreases the concrete's.

- Open time: A cement material's workability time is usually associated with setting time, determined by a Vicat. This device is designed to determine the start and end times and cannot be used over time for determining changes in the workability of fresh concrete. Several experiments were conducted using the crash test to track the change in functionality over time. Nevertheless, a crash test to determine the open period is not acceptable. In terms of calculating workability, calculation of sliding force overtime produces more insightful results. The Open-time period is established as the timeframe for maintaining exclusivity by working the fresh concrete for 3D concretes (Le et al. 2012 (a)). This ensures that the open time is when the pump, printability and buildability of the 3D concrete are compatible within reasonable tolerances.

- $\quad$ Contact strength between layers: The software to get a solid structure adherence must be strong when placing the concrete on top of each other. Therefore, the concrete should not be hardened, but instead of hydrating the concrete, the preceding layer should continue when you put the concrete on the ground. In other words, there must be no cold joint. Many researchers have emphasized the importance of the form of the layers to ensure this. It is possible to change the shape of layers by varying the shapes of the printing nozzle (Bos et al. 2016). The printer will rotate around the corners, apart from the size and shape of the dots, to correctly match the corners to the structure. The 3D concrete printer's durability is considered and checked many times before actual printing to provide corners of 90 degrees (Wolfs 2015).

- Aggregates play a crucial role during the 3D concrete phase of the aggregates determine the structure's load-bearing strength. The size of the nozzle varies from $20 \mathrm{~mm}$ to $40 \mathrm{~mm}$. The width of the aggregates should, therefore, be greater than 4-6 mm to avoid obstruction of the nozzle. Additionally, the use of coarse aggregates contributes to instability in the printing system, allowing the framework formation to collapse (Nadarajah 2018).

- Water-cement ratio: Many scientists have experimented with the water-cement ratios 


\section{International Journal of Engineering Applied Sciences and Technology, 2021 Vol. 5, Issue 12, ISSN No. 2455-2143, Pages 39-48 \\ Published Online April 2021 in IJEAST (http://www.ijeast.com)}

between $0.25-0.44$. It is necessary to use the minimum amount of water with superplasticizers for better concrete adhesion. Furthermore, it was determined that adding materials such as fly ash, silica fume and slag could benefit the mixture if 5 to 30 percent of the total binder volume were added (Nadarajah 2018).

Since then it has not been understood that 3D concrete should be absorbed from the nozzle into the layer top structural components, there is little knowledge about the material structure and properties of 3D concrete. The product of the mixture includes a plasticizer, so that material with small particle size will move freely from the diameter of the container.

\section{CHALLENGES AND OPPORTUNITIES}

3D concrete printing technology, an automated production, has become a major focus for the manufacturing industry. In contrast, AM's model is a new revolution in the building industry. 3D Concrete Printing Technology is not an integrated technology yet that is in the process of solving all construction problems. Although a number of studies have been carried out on the construction sector, this technology also has to be continuously worked on to understand its role and its maximum potential in the construction industry. 3D printing is used in robot technology to simultaneously overcome these limitations (Da chutter et al. 2019; Camacho ei aI. 2018; Wu ei al. 2016).

In early studies, 3D printing techniques are considered not to be ideal for large-scale models or structures (Gibson et al. 2002). Such estimates were compounded due to the small size of $3 \mathrm{D}$ printers used in the initial phase of the technology. On the other hand, with the development of new 3D printers in recent years, such large-scale 3D printers have been used to manufacture many large-scale models or structures $(\mathrm{Wu}$ et al. 2016). Figure 4 displays the specimens.

The materials play a very important role in $3 \mathrm{D}$ printing as well as the scale of the printers. Nearly all of the AM production work is based on concrete in the construction industry. This has resulted in very limited availability of the material palette currently owned. High performance for using 3D engineering for large-scale models and structures must be the strength and structural properties of the printed objects using the new printing materials. Nevertheless, it is known that 3D printing cannot be used in large-scale models and structures due to the difficulty of having high-strength printing materials. But it has been proven as effective as modified and high-strength printing materials in various materials. Besides, in large-scale printed concrete structures, the strength of traditional concrete is obtainable Looking at the current state of the $3 \mathrm{D}$ imprimable materials, the emphasis on the material properties is still not adequate.
The concrete studies were primarily based on initial strength and durability, especially the load-bearing capacity parameter. While the materials used for 3D printing technology are examined in terms of their load resistance strength, their fire resistance, toughness and thermal properties are rarely examined. Some mechanical and physical properties may be incorrectly detected when the quality of the material is tested in detail. A suitable mixture model and active healing steps should be established to ensure the expected performance, according to the information obtained from the studies. Although there are some advances in 3D concrete processing, due to their physical-chemical structure, the mixtures are very sensitive. It means that a transition may entail a new adaptation of the concrete mix or additive form of cement or aggregate. For order to be used as 3D printing material, products must also have some basic properties, such as a fast cure. The concrete would also be used as a printing medium so that it could be extruded to an appropriate degree to be separated from the printer's nozzle. Beton layers should conform to each layer while casting concrete must feature enough workability and buildability to support the top layers and avoid collapse (Labonnote et al. 2016; Wu et al. 2016). (Labonnote et al. 2016).

Interface zones formed between the layers will have a significant impact on the mechanical performance, bonding behaviour, bearing and durability of the 3D printed structures/elements product. Current design criteria for structural and strength accept concrete as a homogeneous material. Nevertheless, this is not appropriate due to the layered structure and weaker interface for 3D printed concrete elements with anisotropic behaviour. It will be necessary to consider the layered system structure requiring new design models, such as the shear load at the structural design stage (Da chutter et al. 2019) To order for 3D printed concrete to be used with anisotropic activity, concrete current standards should be updated. The lack of appropriate standards and guidelines for measuring quality in the concrete industry are barriers to the growth and enhancement of digital production. In addition, comparing implementations and studies in the literature is difficult in this case. RILEM promotes engineering for digital concrete. Apart from various research organizations, companies and universities are also establishing AM engineering standards (Camacho et al. 2018; Da SChutir et al. 2018).

The construction industry is worldwide responsible for significant impacts on the environment. To that the high environmental impacts generated by the conventional construction process, which is exacerbated by the fact that people are more concerned with sustainability, creative construction methods need to emerge. A cost-effective construction process is the process of additive manufacturing, which decreases 


\section{International Journal of Engineering Applied Sciences and Technology, 2021 \\ Vol. 5, Issue 12, ISSN No. 2455-2143, Pages 39-48 \\ Published Online April 2021 in IJEAST (http://www.ijeast.com)}

energy consumption, resource demands, and $\mathrm{CO} 2$ emissions (Da SChutir et al. 2018).

The results of the environmental assessment confirmed that, compared to conventional construction, digital production for highly complex geometry structures offers high environmental benefits. As shown in the figure below, the environmental impact of digital production does not change due to the increasing complexity of the structure. In the conventional construction process, as the complexity of geometry increases, more resources will be needed and more waste building materials will emerge and the construction process will be extended.. AM is a method of construction that works in harmony with the environment, producing less waste and allowing recycling by reusing most of the waste for different works in the future. Complex geometries can only be considered to be not always helpful. However, as the complexity of the structural geometry to be achieved by optimization increases, the use of material can be significantly reduced by using the highest quality material used. Digital manufacturing tends to be quite favourable for the construction of this structure compared to conventional construction with minimal environmental impact and costs. Therefore, the additive manufacturing of buildings in challenging conditions where human access is impossible, unable or dangerous is expected to have significant benefits. Possible incidents in such systems can thus be avoided (Da SChutir et al. 2018; Labonnote et al. 2016).

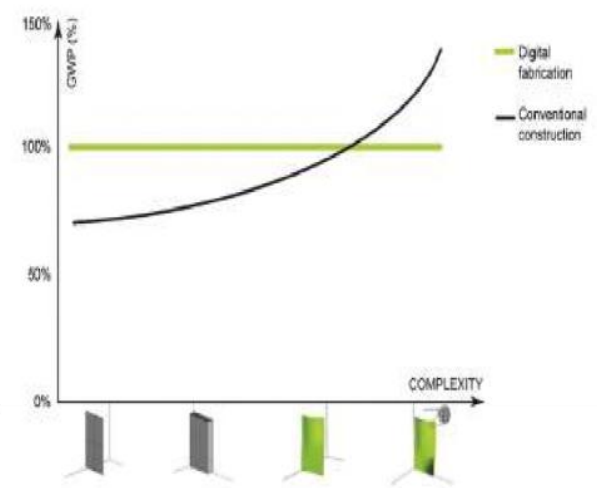

Fig -5. Comparison of environmental impacts of conventional construction and digital production, depending on building complexity (Da SChutir et al. 2018; Agusti-Juan et al. 2017).

As the use of complex geometry moulds increases, construction difficulties increase, the time and manpower needed to build and manufacture the mould also increase, and as a result, the entire construction process is extended. The benefits of this technology are that it does not require moulds, reduces the need for work and allows large-scale structures to be produced in a short time. However, due to the advantages of the construction process and the high degree of optimum use, the technologic can significantly reduce the building weight and the expense of the construction materials used by considerably reducing the number of materials used, optimization of the components. In particular, cost reduction in the construction of complex structures compared to conventional methods is required. The cost of $3 \mathrm{D}$ printing structures is also expected to become independent of the increase in structural complexity. Agusti-Juan et al (2017) also examined this situation. His analysis of potential benefits for complex structures of digital manufacturing: environmental assessment of robotically manufactured cement wall (Camacho et al. 2018; Da SChutir et al. 2018; Labonnote et al. 2016).

The $3 \mathrm{D}$ printing gives the construction industry, which is always considered to be an industry with minimal mass customization, a lot of mass customization alternatives. The construction sector can be opened up to a wide range of product customization con trary to conventional methods of restricting the creativity of architects. The effectiveness of 3D printing in the construction industry depends on two factors: the nature of the needs of the consumer and the degree of the desire of the customer. For example, mass customization in the house building sector has been the key marketing strategy in the construction industry in Korea for the past 30 years.. Researchers agree that applications for construction using 3D printing technology will gradually increase shortly (Wu et al. 2016; Labonnote et al. 2016).

In addition,

3D printing technology can easily produce a complex geometry structure that is difficult and expensive to build using conventional methods using standard construction procedures. 3D printing technology will accelerate the production of revolutionary constructions that are not technically and economically available a few years ago. New structural models need to be explored, which will increase the potential of 3D printing technology in the construction sector and demonstrate their benefits (Camacho et al. 2018; Labonnote et al. 2016). This brings many benefits, such as reducing material consumption and the impact on the environment, achieving esthetic appearance and limitlessness Designs. It must be kept in mind that 3D-based buildings must comply with structural rules to maintain the levels of safety and quality required by current building codes. The method will encourage more innovative designs, but they will have to be more rational.

\section{CONCLUSION AND RECOMMENDATIONS}

The 3D printing technique for cement materials is a promising approach that can revolutionize the obvious benefits of low cost, high efficiency, automatic construction, and architectural design independence, building requirements and risk reduction in conventional building and construction processes during construction. As a consequence, it may not be ideal for printed materials and structures to use the specifications and techniques of testing for traditional concrete. The 


\section{International Journal of Engineering Applied Sciences and Technology, 2021 \\ Vol. 5, Issue 12, ISSN No. 2455-2143, Pages 39-48 \\ Published Online April 2021 in IJEAST (http://www.ijeast.com)}

standards and new regulations will need to be updated to evaluate and test the mechanical efficiency of concrete 3D printing, as well as to develop new theoretical models to appraise their structural behavior. In 3D printing components and structures to be able to withstand all loads, new design specifications and measurement requirements are extremely important.

This paper explores 3D concrete engineering by summarizing the $3 \mathrm{D}$ concrete printing system in terms of its potential opportunities and challenges;

-3D printing technology needs to be developed for mechanical strength, strengthening, curing and durability. The performance of 3D concrete printing is studied in some respects. For 3D concrete printing, specifically on in-situ applications, the manufacturing conditions should be investigated.

- 3D concrete has some feasible features such as flowability. These characteristics vary from traditional concrete. Therefore, the development of 3D concrete should be performed with greater care by taking these characteristics into account.

Obtaining printable cement materials compliant with 3D printers is one of the fundamental challenges. Because of insufficient rheological and rigid properties, high-performance and highly durable cement-based products currently available cannot be treated directly in a printing process. The rheological properties of cement, setting time and temperature of hydration should be appropriate with $3 \mathrm{D}$ concrete open time.

There is, however, no standard for $3 \mathrm{D}$ concrete printing technology around the world. To test the mechanical behavior of samples, components and structures effectively and reliably made with cement material through 3D printing, fundamental and unified standards must be established.

The initial cost of concrete printing technology is high due to the high cost of 3D printer machines. 3D concrete printing provides many potential costeffectiveness advantages for construction processes compared to conventional construction methods, taking into account the different cost elements (labor, equipment, materials, design and planning costs).

Design optimization in 3D technology increases the complexity of the shape but also reduces the use of material when considering the impact on the environment. As a consequence, 3D engineering is expected to achieve better environmental quality over the entire service life of structures with the same features.

- Continuous research will focus on interdisciplinary work involving the science of materials, methods of production, robotics, architecture and design to solve these problems. Once problems with 3D concrete printing technology are overcome ,3D printing in the field of construction will achieve its full prospect. The following steps are recommended for further development of $3 \mathrm{D}$ concrete printing in the future.
- Partnership with academia should be increased so that new and improved 3D concrete printers can gain an experience and partnership with conventional vendors to enable concrete $3 \mathrm{D}$ printing.

Development of high-rise buildings in the future, reinforcements should be integrated into the $3 \mathrm{D}$ printed structure.

To build environmentally friendly buildings, the use of recycled materials in $3 \mathrm{D}$ concrete processes should be increased.

Due to its versatile nature, the use of 3D PC should be increased in the decipline of architecture.

Integration of 3D concrete printing with digital technology to improve future building performance.

\section{- ACKNOWLEDGEMENT}

The paper is focused on 3D concrete printing technology and industrial mechanics. It is the cornerstone of Cyprus International University's Masters of Civil Engineering. First of all, I would like to thank my supervisor sincerely. Professor Mohammed Ali MOSABERPANAH has always assisted me in the ongoing support for my work, his patience, his inspiration, and his tremendous knowledge of practical engineering.

\section{REFERENCES}

[1] Austin, W., \& Khoshnevis, B. (1988, May). Intelligent simulation environments for system modeling. In Institute of Industrial Engineering Conference.

http://www.astm.org/DATABASE.CART/HISTO RICAL/F2792-10.htm

[2] Bos, F., Wolfs, R., Ahmed, Z., \& Salet, T. (2016). Additive manufacturing of concrete in construction: potentials and challenges of 3D concrete printing. Virtual and Physical Prototyping, 11(3): 209-225.

[3] Camacho, D. D., Clayton, P., O'Brien, W. J., Seepersad, C., Juenger, M., Ferron, R., \& Salamone, S. (2018). Applications of additive manufacturing in the construction industry $A$ forward-looking review. Automation in construction, 89: 110-119.

[4] Campbell, T., Williams, C., Ivanova, O., \& Garrett, B. (2011). Could 3D printing change the world. Technologies, Potential, and Implications of Additive Manufacturing, Atlantic Council, Washington, DC, 3.

[5] Cesaretti, G., Dini, E., De Kestelier, X., Colla, V., \& Pambaguian, L. (2014). Building components for an outpost on the Lunar soil by means of a novel $3 D$ printing technology. Acta Astronautica, 93: 430-450.

[6] Chang, S. H. (2016). Exploring the evolution of additive manufacturing industry: a study of stakeholder requirements and architectural 


\section{International Journal of Engineering Applied Sciences and Technology, 2021 \\ Vol. 5, Issue 12, ISSN No. 2455-2143, Pages 39-48 \\ Published Online April 2021 in IJEAST (http://www.ijeast.com)}

analysis of Desktop three-dimensional printing Segment. Ph. D. Thesis. Massachusetts Institute of Technology.

[6] Da SChutir, G., Lesage, K., Mechtcherine, V., Nerella, V. N., Habert, G., \& Agusti-Juan, I. (2018). Vision of $3 D$ printing with concrete technical, economic and environmental potentials. Cement and Concrete Research.

[7] Gebler, M., Uiterkamp, A. J. S., \& Visser, C. (2014). A global sustainability perspective on $3 D$ printing technologies. Energy Policy, 74: 158-167.

[8] Gibson, I., Kvan, T., \& Wai Ming, L. (2002). Rapid prototyping for architectural models. Rapid prototyping journal, 8(2): 91-95.

[9] Hopkinson, N., Gao, Y., \& McAfee, D. J. (2006). Design for environment analyses applied to rapid manufacturing. Proceedings of the Institution of Mechanical Engineers, Part D: Journal of Automobile Engineering, 220(10): 1363-1372.

[10]Justnes, H., \& Martius Hammer , T. A (2016) Surdurulebilirlik, Beton Inovasyondaki Oncu Rolu hazirBeton, 23: 77-82.

[11] Khoshnevis, B., \& Bekey, G. (1998). Centralized sensing and control of multiple mobile robots. Computers \& industrial engineering, 35(3-4): 503506.

[12] Khoshnevis, B., \& Zhang, J. (2012). Extraterrestrial construction using contour crafting. Solid Freeform Fabrication Proceedings; University of Texas: Austin, TX, USA, 250-259.

[13] Labonnote , N ,Ronnquist ,A Manum ,B \& Ruther P.(2016) additive construction state -of-the-art, challenges and opportunities. Automation in Construction, 72: 347-366.

[14] Le, T. T., Austin, S. A., Lim, S., Buswell, R. A., Gibb, A. G., \& Thorpe, T. (2012)(a). Mix design and fresh properties for high-performance printing concrete. Materials and structures, 45(8): 12211232.

[15] Le, T. T., Austin, S. A., Lim, S., Buswell, R. A., Law, R., Gibb, A. G., \& Thorpe, T. (2012)(b). Hardened properties of high-performance printing concrete. Cement and Concrete Research, 42(3): 558-566.

[16]Lim, S., Le, T., Webster, J., Buswell, R., Austin, A., Gibb, A., \& Thorpe, T. (2009). Fabricating construction components using layered manufacturing technology. In Global Innovation in Construction Conf. (pp. 512-520).

[17]Lim, S., Buswell, R. A., Le, T. T., Wackrow, R., Austin, S. A., Gibb, A. G., \& Thorpe, T. (2011). Development of a viable concrete printing process.

[18]Lim, S., Buswell, R. A., Le, T. T., Austin, S. A., Gibb, A. G., \& Thorpe, T. (2012). Developments in construction-scale additive manufacturing processes. Automation in construction, 21: 262268.
[19] Nadarajah, N. (2018). Development of concrete 3D printing. Master thesis, Aalto Uinversity School of Engineering, Building Technology, Finland.

[20] Ozalp, F, Yilmaz , H. D., \&Ysar , S. (2018) 3D YaZici Teknolojisine Uygun Surdutulebilir Ve Yenilikci BEtonlarin [21] Gelistirilmesi . HAzir Beton Dergisi , Eylul 2018, 62-70 (in Turkish with english )

[22] Papachristoforou, M., Mitsopoulos, V., \& Stefanidou, M. (2018). Evaluation of workability parameters in $3 D$ printing concrete. Procedia Structural Integrity, 10:155-162.

[23] Pegna, J. (1997). Exploratory investigation of solid freeform construction. Auto. in construction, 5(5): 427-437.

In: 9. Ulusal Beton Kongresi, pp. 431-441. Antalya, Turkey.

[24] Van Damme, H. (2018). Concrete material science: past, present, and future innovations. Cement and Concrete Research. 112, 5-24

[25] Wolfs, R. (2015). 3D printing of concrete structures.

Graduation thesis, Eindhoven University of Technology,

[26] Department of the Built Environment Master Architecture, Building and Planning Specialization Structural Design, Netherlands.

[27] Wu, P., Wang, J., \& Wang, X. (2016). A critical review of the use of 3-D printing in the construction industry. Automation in Construction, 68: 21-31.

[28]Radiolaria designed by Andrea Morgante and printed with D-shape. Date accessed is March, 2019.https://d-shape.com/bwg_gallery/radiolaria/,

[29]representation of Detached Houses produced by CC, Date accessed is March, 2019.http://contourcrafting.com/buildingconstruction, Schematic

[30] Multi-storey houses produced in China by Winsun, Date accessed is March, 2019.http://www.winsun3d.com , [31] world's First 3d Printed Laboratory in Dubai $\mathrm{R} \% \mathrm{D}$ Laboratory by $\mathrm{CyBe}$, Date accessed is March,

2019.https://cybe.eu/portfolioitem/rdrone laborato ry 3dprinting on-site in the desert of dubai/

[32]3D concrete printing house produced in Russia by Apis Cor, Date accessed is March, 2019. https://www.apis-cor.com/en/about/news ,

[33]Castle in Minnesota, USA and Hotel suite interior in the Philippines by Total Kustom, Date accessed is March, 2019http://www.totalkustom.com/3dcastle-completed.html,

[34] Gaia is a sample home by WASP, Date accessed is March, 2019. https://www.3dwasp.com/en/3dprinted-house-gaia/,

[35] En-Provence by XtreE, This 4m-high post supports the playground roof of a school in Aix-enProvence, France, Date accessed is March, 2019 http://www.xtreee.eu/post-in-aix-en-provenc. 
Published Online April 2021 in IJEAST (http://www.ijeast.com)

[36] Office building in Dubai by Winsun, Date accessed is March, 2019. http://www.officeofthefuture.ae/

[37] The first 3D printed pedestrian bridge in China by Tsinghua

University,DateaccessedisMarch,2019.http://news. tsinghua.edu.cn ,

[38] Bridge produced by 3D concrete for cyclists in 2017 by Eindhoven University of Technology, Date accessed March,2019..https://www.dezeen.com/2017/10/27 /worlds-first-3d-printed-concrete-bridgebicyclesbam-infra-netherlands/,

[40] Urban furniture by Iston Date accessed is March, 2019.

https://www.thbb.org/media/299617/makale149.p $\underline{\text { df }}$ 